This is the post-print version produced by the authors. The final publication is available at http://www.springerlink.com/openurl.asp?genre=article\&id=doi:10.1007/s10750-015$\underline{2205-5}$

Ferrer-Maza, D.; Muñoz, M.; Lloret, J.; Faliex, E.; Vila, S.; Sasal, P. (2015). Health and reproduction of red mullet, Mullus barbatus, in the western Mediterranean Sea. Hydrobiologia, 753: $189-204$. http://dx.doi.org/10.1007/s10750-015-2205-5 


\title{
Health and reproduction of red mullet, Mullus barbatus, in the western Mediterranean Sea
}

\author{
Dolors Ferrer-Maza $^{\mathrm{a} 1}$, Marta Muñoz ${ }^{\mathrm{a}}$, Josep Lloret ${ }^{\mathrm{a}}$, Elisabeth Faliex ${ }^{\mathrm{b}}$, Sílvia Vila $^{\mathrm{a}}$, Pierre Sasal $^{\mathrm{c}}$ \\ ${ }^{a}$ Department of Environmental Sciences, University of Girona, E-17071 Girona, Spain \\ ${ }^{\mathrm{b}}$ University of Perpignan Via Domitia, Centre de Formation et de Recherche sur les \\ Environnements Méditerranéens, UMR 5110, F-66860, Perpignan, France \\ ${ }^{c}$ Laboratoire d'Excellence Corail, CRIOBE, USR 3278 - CNRS - EPHE, CBETM - Université \\ de Perpignan \& BP 1013 - 98729, Papetoai, Moorea, French Polynesia \\ ${ }^{1}$ Corresponding author. Email: dolors.ferrer.maza@gmail.com; Tel.: +34 972418 269; Fax: +34 \\ 972418150
}

\begin{abstract}
The reproductive and general health of exploited fish stocks is an essential element of sustainable and profitable fisheries. The main purpose of this study is to assess the relationships between reproduction and two important parameters of fish health (parasitism and energy reserves) in female specimens of red mullet, Mullus barbatus, from the western Mediterranean Sea. We present new data for this species on (i) the prevalence and intensity of infection by metazoan parasites; (ii) the total lipid content in muscle and gonads as a measure of condition and (iii) fecundity and egg quality as a measure of their reproductive capacity. The results show that $M$. barbatus is a batch spawner with an income breeding strategy, an asynchronous development of oocytes and indeterminate fecundity. The results also indicate that the three most abundant and prevalent parasites significantly affect the condition and reproduction of $M$. barbatus. Specifically, the digenean, Opecoeloides furcatus, causes a reduction in the female's energy reserves while the nematodes, Hysterothylacium fabri and $H$. aduncum, produce a rise in egg production but impair egg quality. These implications of the relationships between parasitism, fish health and fish reproduction should be taken into consideration in the assessment and management of exploited species.
\end{abstract}

Keywords: egg quality, energy reserves, fecundity, metazoan parasites, reproductive strategy 


\section{Introduction}

Parasitism is usually defined as a non-mutual symbiotic relationship between species, where the parasite benefits at the expense of the host. In theory, therefore, parasitism should produce deleterious effects on fish health because the parasites drain energy from the fish that would otherwise be used to sustain the fish's condition, growth or reproduction. However, it appears that through the coevolution of host and parasite, a dynamic equilibrium has arisen between fish and their parasites (Barret, 1986). Indeed, in most cases, parasites do not cause severe effects on their hosts because this would impair their chances of reaching the following stage of their life cycle or of reproducing.

Lipid storage and dynamics within the organism are an important aspect of fish health (Adams, 1999). The energy reserves of fish are a highly significant indicator of their condition and may have important implications in research into fish life-history traits and, consequently, for stock productivity and fisheries in general (reviewed by Lloret et al., 2012a, 2014). In particular, the maternal condition has been identified as an important factor in determining egg production and egg condition in a number of fish species, e.g. Atlantic cod, Gadus morhua L. 1758, and haddock, Melanogrammus aeglefinus L. 1758, (Saborido-Rey et al., 2003; Alonso-Fernández et al., 2009). However, little attention has been paid to the effects of parasitism on maternal condition or, consequently, on reproductive capacity. There are some studies on the relationships between parasitism and condition (e.g. Ondracková et al., 2010; Guidelli et al., 2011; Francová \& Ondračková, 2013) and also some that include reproductive variables (e.g. Sasal et al., 2001; Bagamian et al., 2004; Bean \& Bonner, 2009). However, most of these studies used simple morphometric indices of condition and have focused on freshwater fish species or on the effects of a single species of parasite.

With regard to marine exploited species, information on the effects of parasites on the energy reserves is limited to a few studies on northwestern Atlantic cod, Gadus morhua, (Khan \& Lacey, 1986), young-of-year common sole, Solea solea L. 1758, in the northeastern Atlantic Ocean (Durieux et al., 2007), anchovy, Engraulis encrasicolus L. 1758, in the Black Sea (Shchepkina, 1980) and Japanese anchovy, E. japonicus Temminck \& Schlegel 1846, (Sajiki et al., 1992). To our knowledge, the only study into the relationships between parasitism, energy reserves and reproductive capacity of an exploited marine species is our previous work on the European hake, Merluccius merluccius L. 1758, in the northwestern Mediterranean Sea (FerrerMaza et al., 2014). In short, little is known about the effects of parasites on the condition and the productivity of marine fishes.

Red mullet, Mullus barbatus L. 1758, is a demersal species that inhabits sandy and muddy bottoms of the continental shelf of the Mediterranean Sea, including the Black Sea, and also the eastern Atlantic from Scandinavia to Senegal (Fischer et al., 1987). This species is an important component of the Mediterranean demersal resources exploited by bottom trawling and smallscale fisheries (Fischer et al., 1987; Tserpes et al., 2002). The stocks of M. barbatus are highly vulnerable to recruitment changes (Tserpes et al., 2002) and all stocks in the Mediterranean Sea are currently considered overexploited (FAO, 2012). Despite the importance of energy reserves in estimating the productivity of exploited populations, the lipid content of $M$. barbatus has rarely been considered in the context of fishery ecology (Lloret et al., 2005, 2007; Roncarati et al., 2012). The available knowledge on the reproductive biology of $M$. barbatus is also very scarce and based mainly on macroscopic observations or simple morphometric indices (Desbrosses, 1935). There have been only a few attempts to estimate its fecundity (Tirasin et al., 2007; Aydın \& Karadurmuş, 2013) and a single histological study describing the different stages 
of oocyte development (Kokokiris et al., 2014). Therefore, little information exists on the spawning strategy or the oocyte recruitment pattern. The metazoan parasites of $M$. barbatus have, in contrast, been widely reported, mostly in studies aimed at identifying a single species or group of parasites (e.g. Martínez-Vicaria et al., 2000; Ramdane et al., 2013), but also in the reporting of a list of the metazoan parasite fauna of this species (Carreras-Aubets et al., 2011, 2012).

The main purpose of this study is to assess the relationships between reproduction and two important parameters of fish health (i.e. parasitism and energy reserves) with regard to $M$. barbatus in the western Mediterranean Sea. By considering these relationships, this study also sheds light on several essential but undocumented aspects of the reproduction of this species, such as the oocyte recruitment pattern or the spawning strategy. The outcomes are discussed from a biological and ecological perspective in order to provide useful information for improving stock assessment and management of this economically valuable species.

\section{Materials and methods}

\section{FISH SAMPLING}

A total of 335 mature female specimens of M. barbatus were collected from January 2010 to May 2012, on a quarterly basis in order to obtain representatives from each ovarian developmental phase. However, most of the sampling events (89\%) were concentrated in the second quarter, i.e. the spawning period of the species, because this is when the reproductive capacity of females (fecundity and egg quality) can be measured. Moreover, as the females presumably need to allocate more of their energy to egg production during this period, they should be more sensitive to an eventual effect of parasites on their overall condition. Specimens were caught via bottom trawls (from MEDITS trawl survey and commercial trawlers) at depths ranging from 30 to $250 \mathrm{~m}$ along the western coast of the Spanish Mediterranean Sea (FAOGFCM geographical sub-area GSA-06, Northern Spain) (Fig. 1). For each individual, the total body length $\left(L_{\mathrm{T}}\right)$ was recorded $( \pm 0.1 \mathrm{~cm})$, as well as total body mass $\left(M_{\mathrm{T}}\right)$, eviscerated body mass $\left(M_{\mathrm{E}}\right)$ and gonad mass $\left(M_{\mathrm{G}}\right)( \pm 0.1 \mathrm{~g})$. The total lengths of the specimens sampled ranged from 12.5 to $26.9 \mathrm{~cm}$ (mean \pm S.D. $=19.5 \pm 2.5$ ). All the muscle tissue from the left side of each specimen and one ovary lobe were removed and frozen at $-20^{\circ} \mathrm{C}$ for subsequent lipid content determination, while the second ovary lobe was fixed in $4 \%$ buffered formaldehyde for histological processing and subsequent fecundity estimation.

\section{PARASITISM EVALUATION}

All the specimens were examined for metazoan parasites prior to the removal of muscle and gonads for lipid content determination and histology. The entire viscera were removed from the body cavity, and the gills and internal organs (heart, oesophagus, stomach, intestine, spleen, gallbladder, liver, and gonads) were examined using a stereomicroscope. The macroparasites were collected and washed with a saline solution $(0.8 \% \mathrm{NaCl})$. They were first observed alive and then fixed in permanent preparations. Cestodes, nematodes and isopods were preserved in $70 \%$ ethanol, whereas digeneans were fixed in Bouin's solution under slight coverslip pressure. If necessary, and depending on the taxonomic group, the specimens were cleared in lactophenol or stained with borax carmine and mounted in Canada balsam. Parasites were morphologically identified to the lowest taxonomic level possible following the available keys and descriptions, such as Gibson et al. (2002), Jones et al. (2005) and Bray et al. (2008) for digeneans or Naidenova \& Nikolaeva (1968), Petter et al. (1984) and Petter \& Maillard (1987, 1988) for nematodes. Since the identification of each species of parasite is based on adult features, some parasite larvae could not be identified to the species level. These included immature digeneans, 
L3 larvae of Contracaecum sp., Tetraphyllidean plerocercoids and the praniza larvae of the gnathiid isopods (Gnathia sp.).

As described by Bush et al. (1997), the prevalence of parasites $\left(P_{\mathrm{P}}\right)$ was calculated as the proportion of fish infected with a particular parasite species and the individual intensity of the infection as the number of individuals of a particular species in a single infected host. The mean intensity was calculated as the average number of parasites of a particular species found in the infected hosts. The median intensity and its $95 \%$ confidence interval (C.I.) were also calculated.

\section{ENERGY RESERVES DETERMINATION}

A subsample of muscles $(n=156)$ and ovaries $(n=87)$ large enough to perform the lipid extraction (minimum required $=4 \mathrm{~g}$ of tissue) were selected to assess the condition (indicated by energy reserves) of $M$. barbatus. Females whose gonads were large enough to perform lipid extraction appeared only in May and June (spawning season). In that season, corresponding to a sensitive critical period of the fish life cycle, i.e. reproduction, more analyses of muscular lipid reserves were performed in order to optimize the detection of potential effects of parasitism on the condition of $M$. barbatus. In muscle as well as in gonads, the total lipid content (\% wet mass) was determined following the Soxhlet method described by Shahidi (2001). A lipid musculosomatic index $\left(I_{\mathrm{LM}}\right)$ and a lipid gonado-somatic index $\left(I_{\mathrm{LG}}\right)$ were calculated as $I_{\mathrm{LM}}=100 \mathrm{ABS}$ $M_{\mathrm{E}}{ }^{-1}$ and $I_{\mathrm{LG}}=100 A B S_{\mathrm{G}} M_{\mathrm{E}}{ }^{-1}$, where $A B S_{\mathrm{M}}$ and $A B S_{\mathrm{G}}$ are the absolute lipid content in muscle and gonads, respectively, which were obtained by multiplying the respective lipid contents (\% wet mass) by the wet mass of either the muscle or the gonads. The muscle wet mass $\left(M_{\mathrm{M}}\right)$ was estimated using the equation $M_{\mathrm{M}}=0.64 \cdot M_{\mathrm{E}}-0.9\left(R^{2}=0.99, n=98, P<0.0005\right)$ given by Lloret et al. (2007) for $M$. barbatus in the northwestern Mediterranean. The $I_{\mathrm{LM}}$ was considered as an indicator of $M$. barbatus condition because the muscle tissue constitutes the main source of lipid reserves in this species (Lloret et al., 2007), whereas the $I_{\mathrm{LG}}$ was used as an indicator of the energy reserves that were being used in the development of the gonads.

\section{REPRODUCTIVE CYCLE DESCRIPTION AND ATRESIA EVALUATION}

The gonado-somatic index $\left(I_{\mathrm{G}}\right)$, which is the relation between the gonad mass $\left(M_{\mathrm{G}}\right)$ and the eviscerated mass $\left(M_{\mathrm{E}}\right)$ of the females, was calculated as $I_{\mathrm{G}}=100 M_{\mathrm{G}} M_{\mathrm{E}}^{-1}$. The mass of ovaries increases with vitellogenesis and hydration of eggs, thus this index provides information on the fish reproductive cycle. Furthermore, one ovary lobe from each $M$. barbatus ovary was fixed and sliced transversely in its midsection. The resulting slices were embedded in paraffin, cut into 8$10 \mu \mathrm{m}$ sections, and stained with both hematoxylin-eosin and Mallory's trichrome stains. The latter staining method highlights the zona radiata and its continuity and facilitates the detection of degenerating oocytes which will not be spawned, i.e. atretic oocytes (Muñoz et al., 2010). To describe the developmental stage of the oocytes, we used the terminology employed by (Lowerre-Barbieri et al., 2011): primary growth (PG), cortical alveolar (CA), vitellogenesis (VIT1 and VIT2), maturation (OM), hydrated oocytes $(\mathrm{H})$ and atresia. On the other hand, we used the presence of specific histological markers to classify our specimens into four ovarian developmental phases, following (Brown-Peterson et al., 2011): regenerating (REG) - sexually mature but reproductively inactive; developing (DEV) - gametes begin to develop; spawning capable (SC) - advanced, developed gametes ready for the spawning season; and regressing (REGR) - massive atresia which indicates the end of the reproductive cycle.

The prevalence of atresia $\left(P_{\mathrm{A}}\right)$ was defined as the proportion of females with observed $\alpha$-atretic oocytes, and the relative intensity of atresia $\left(I_{\mathrm{A}}\right)$ was calculated for each female as the number of $\alpha$-atretic oocytes divided by the total number of vitellogenic oocytes ( $\alpha$-atretic and normal). Three different fields from different histological slides of each specimen were analysed. 


\section{FECUNDITY AND EGG QUALITY ESTIMATIONS}

Ovaries containing hydrated oocytes, but which did not have recent post-ovulatory follicles (POFs), were selected to assess the fecundity $(n=89)$. Slices from the central area of the ovaries were weighed $( \pm 0.1 \mathrm{mg})$ and the oocytes were separated using a washing process, as described by Lowerre-Barbieri \& Barbieri (1993), and sorted by size through several sieves (from 400 to $600 \mu \mathrm{m})$. The oocytes were counted and their diameters were measured using a computer-aided image analysis system (Image-Pro® Plus 5.1, Media Cybernetics, Inc., Bethesda, MD, USA).

In addition to obtaining the oocyte diameter-frequency distributions from the above procedure, we wanted to investigate this species' spawning pattern (total spawner vs. batch spawner) and its oocyte recruitment pattern (synchronous vs. asynchronous oocyte development and determinate vs. indeterminate fecundity). To this end, 10 ovaries, identified as being from specimens in the spawning capable phase in the previous histological analysis, were randomly selected and used to measure the mean diameter of oocytes in the different stages of development. Oocytes in primary growth (PG), cortical alveolar (CA), vitellogenesis (VIT1 and VIT2) and maturation $(\mathrm{OM})$ stages $(n=379)$ were measured individually in histological sections, whereas the hydrated oocytes $(\mathrm{H})(n=247)$ were measured using the aforementioned image analysis system, since they usually show an irregular shape in the histological preparations.

Investigation of the spawning pattern showed that $M$. barbatus is a batch spawner. Thus, in order to assess the reproductive capacity, we also estimated the batch fecundity $\left(F_{\mathrm{B}}\right)$, defined as the number of eggs spawned per batch, and the relative batch fecundity $\left(F_{\text {Brel }}\right)$, defined as the value of batch fecundity per gram of eviscerated female body mass.

Finally, the dry mass of hydrated oocytes was used as an indicator of egg quality. Samples of 200 oocytes in late maturation were removed from the ovaries mentioned above $(n=89)$ and weighed $( \pm 0.1 \mathrm{mg})$ after drying for $24 \mathrm{~h}$ at $110^{\circ} \mathrm{C}$. The mean dry mass of oocytes $\left(M_{\mathrm{DO}}\right)$ was calculated by dividing the sample's dry mass by the number of oocytes in the sample.

\section{DATA ANALYSIS}

The aggregated nature of parasite distributions leads to the concentration of a high proportion of parasites in a few host individuals. As argued by Rózsa et al. (2000), it is useful to report the confidence interval (C.I.) for the median intensity of infection. For this reason, a 95\% C.I. was calculated, by the $B C a$ method with 2000 bootstrap replications, using the free Quantitative Parasitology 3.0 software (Reiczigel \& Rózsa, 2005). This software, which was developed to manage the particularly left-biased frequency distribution of parasites, was also used to compare the prevalences (Fisher's exact test) and the median intensities (Mood's median test) for each parasite species through the different ovarian developmental phases of the hosts. A false discovery rate (FDR) approach was used to counteract the problem of multiple comparisons (Benjamini \& Hochberg, 1995; Verhoeven et al., 2005).

A general linear model (GLM) was used to determine the effects of total body length $\left(L_{\mathrm{T}}\right)$, year, latitude and depth of capture, on the condition and reproduction response variables, i.e. lipid musculo-somatic index $\left(I_{\mathrm{LM}}\right)$, lipid gonado-somatic index $\left(I_{\mathrm{LG}}\right)$, relative batch fecundity $\left(F_{\mathrm{Brel}}\right)$ and the dry mass of oocytes $\left(M_{\mathrm{DO}}\right)$. In order to satisfy normality assumptions, $I_{\mathrm{LM}}$ was naturallog-transformed. Explanatory variables were removed by backward elimination and only those which contributed significantly to the model were kept. As shown in Table 1, some of the explanatory variables had significant effects on $I_{\mathrm{LM}}, I_{\mathrm{LG}}$ and $F_{\mathrm{Brel}}$ although no effect on $M_{\mathrm{DO}}$ was 
found. To eliminate this influence and focus on the effects of parasitism, all subsequent analyses were performed with the adjusted values of these response variables.

Once the normality of the data was tested through the different ovarian developmental phases, and rejected, several non-parametric tests were performed to assess the possible effects of parasitism on $M$. barbatus condition (adjusted $I_{\mathrm{LM}}$ and adjusted $I_{\mathrm{LG}}$ ) and reproduction (adjusted $F_{\text {Brel }}$ and $\left.M_{\mathrm{DO}}\right)$. The Mann-Whitney $\mathrm{U}$ test was used to analyse possible differences between infected and uninfected M. barbatus specimens. The Spearman's Rank Correlation coefficient was used to assess the possible relationships between the condition and reproduction parameters and the individual intensity of infection by parasites. These two analyses were performed for the specialist parasites, as well as for the generalist parasites provided the latter appeared in at least 10 specimens, i.e. with a prevalence of infection above 3\% (Table 2). The level of statistical significance adopted was $P<0.05$.

\section{Results}

Of the 335 specimens of $M$. barbatus examined, $276(82.4 \%)$ were infected with at least one metazoan parasite species, with an individual intensity of infection that ranged from 1 to 81 parasites (mean \pm S.D. $=8.38 \pm 10.41)$. A total of 2313 parasites belonging to at least 13 taxonomic groups were identified: six digeneans, five nematodes, one cestode and one isopod (Table 2). The real number of different species might be higher than reported as the groups of larvae classified as "immature digeneans", Contracaecum sp., Tetraphyllidean plerocercoids and Gnathia sp. may include several species. The most prevalent species was the nematode Hysterothylacium fabri (Rudolphi 1819), with a prevalence of $63.9 \%$ and a mean intensity of $3.95 \pm 5.94$ parasites. The species with the highest intensity of infection was the digenean Opecoeloides furcatus (Bremser in Rudolphi 1819), with a prevalence of $55.5 \%$ and a mean intensity of $6.97 \pm 8.66$ parasites (Table 2). The Fisher's exact test showed differences in the prevalence of $O$. furcatus through the different ovarian developmental phases of hosts, being significantly higher $(P=0.002)$ in specimens in spawning capable phase $\left(P_{\mathrm{P}}=61.8 \%\right)$ than in specimens in regenerating phase $\left(P_{\mathrm{P}}=22.2 \%\right)$. No significant differences during different ovarian developmental phases were found in the prevalences of the other parasites. Neither were there any significant differences among the median intensities of any parasite species during the different ovarian developmental phases (Mood's median test, $P>0.05$ ).

In relation to condition, the $I_{\mathrm{LM}}$ values of the 156 specimens analysed for lipids in the muscle ranged from 0.21 to 3.78 (mean \pm S.D. $=1.03 \pm 0.63$ ), whereas the $I_{\mathrm{LG}}$ values of the 87 specimens analysed for lipids in the ovaries ranged from 0.25 to 1.40 (mean \pm S.D. $=0.93 \pm$ 1.83). A Spearman's Rank Correlation test revealed a positive correlation $\left(r_{s}=0.31, n=87, P=\right.$ 0.004 ) between these two variables. All the specimens with ovaries large enough to perform the lipid extraction were in spawning capable phase. The $I_{\mathrm{LM}}$ was analysed through the different ovarian developmental phases (Fig. 2) and a Kruskal-Wallis Test revealed that the distribution of $I_{\mathrm{LM}}$ was the same during each ovarian developmental phases.

The histological analyses of gonads showed that $M$. barbatus maintained a reserve of primary growth (PG) oocytes, which is the first stage of oocyte growth and covers the chromatin nucleolar and the perinucleolar stages. The secondary growth of oocytes begins with the cortical alveolar (CA) stage, which was identified by the formation of the chorion and the presence of small oil droplets and cortical alveoli in the periphery of the cytoplasm. The development of oocytes progressed through several substages of vitellogenesis (VIT1 and VIT2), characterised by the presence of yolk globules and large oil droplets. The oocyte maturation (OM) stage was 
recognised by the fusion of the yolk material, the formation of a single large oil droplet and the migration of the germinal vesicle towards the plasma membrane. Finally, the last maturing event was the hydration $(\mathrm{H})$ substage which is an uptake of fluid by the oocyte that leads to ovulation. As oocytes developed, their size increased gradually, with each stage sharing overlapping diameter ranges with the previous and subsequent stages, except in the case of the hydrated oocytes which had much larger diameters (Fig. 3).

The gonado-somatic index $\left(I_{\mathrm{G}}\right)$, presented a clear seasonal pattern. The highest values were observed in the second quarter, with the highest monthly means in May (11.23 \pm 3.62$)$ and June $(10.97 \pm 2.03)$, while for the rest of the year, the $I_{\mathrm{G}}$ values remained low, with the lowest monthly mean in October $(0.88 \pm 0.24)$. Indeed, the histological examination of the ovaries showed that, overall, females spent the first and fourth quarter in either the regenerating phase (with only PG oocytes present) or the developing phase (with new CA and VIT1 oocytes present) (Fig. 4). All the females in the spawning capable phase (with PG, CA, VIT1, VIT2, OM and $\mathrm{H}$ oocytes present) appeared in the second and third quarter. Females in the regressing phase, which showed massive atresia, were captured in the second quarter, i.e. throughout the spawning season. Ovaries with atretic oocytes were not detected among the individuals in either the regenerating or the developing phases, but females in the spawning capable phase $\left(P_{\mathrm{A}}=11.61 \%\right)$ presented a moderate relative intensity of atresia $\left(I_{\mathrm{A}}=12.15 \pm 10.09 \%\right)$ and, without exception, all the individuals in the regressing phase $\left(P_{\mathrm{A}}=100 \%\right)$ showed high levels of atresia $\left(75 \%<I_{\mathrm{A}} \leq\right.$ $100 \%)$.

Most females in the spawning capable phase showed a bimodal oocyte diameter-frequency distribution with a first component (smaller diameters) containing oocytes in different stages of development, with a gap at around $550 \mu \mathrm{m}$, and a separate second component (larger diameters) containing only oocytes in advanced stage of maturation (Fig. 5). This type of oocyte size distribution is prevalent in batch spawner species, therefore those oocytes that were above 550 $\mu \mathrm{m}$ in size were considered as belonging to the next batch. The batch fecundity $\left(F_{\mathrm{B}}\right)$ ranged from 2408 to 43736 eggs (mean \pm S.D. $=18163 \pm 9778$ ) and was positively related to the size of $M$. barbatus (Fig. 6). The total length-batch fecundity points fitted a power function regression with the following equation $F_{\mathrm{B}}=0.33 \cdot L_{\mathrm{T}}^{3.627}\left(R^{2}=0.75, n=89, P<0.0005\right)$, while the eviscerated mass-batch fecundity points fitted better to a linear regression, $F_{\mathrm{B}}=272.3 \cdot M_{\mathrm{E}}-2554.9\left(R^{2}=\right.$ $0.76, n=89, P<0.0005$ ). The $F_{\text {Brel }}$ ranged from 61 to $371 \mathrm{eggs} \cdot \mathrm{g}^{-1}$ (eviscerated mass) (mean \pm S.D. $=234 \pm 63$ ). Finally, the $M_{\mathrm{DO}}$ ranged from 0.007 to $0.016 \mathrm{mg}$ (mean \pm S.D. $=0.012 \pm$ 0.002 ) and did not present any correlation with the analysed variables.

No significant effect of parasitism was found on either the condition or the reproduction of red mullet in regenerating, developing or regressing phases. However, fish in spawning capable phase showed significant differences in their condition and reproduction that were related to parasitism variables (Table 3). Individuals that were infected by the digenean Opecoeloides furcatus displayed lower median values of $I_{\mathrm{LM}}$ compared with uninfected specimens (MannWhitney U Test, Table 3). There was also a negative correlation between the individual intensity of infection by this parasite and the individual value of $I_{\mathrm{LM}}$ (Spearman's Rank Correlation, Table 3). With regard to the reproduction variables, specimens infected by the nematode Hysterothylacium aduncum (Rudolphi, 1802) showed a higher median value of $F_{\text {Brel }}$ and a positive correlation between the individual intensity of infection by this nematode and the individual value of $F_{\text {Brel }}$. Similar relationships were found between $F_{\text {Brel }}$ and infection by Hysterothylacium fabri, i.e. individuals infected by this nematode displayed higher values of $F_{\text {Brel }}$. However, the individuals infected by $H$. fabri showed lower values of $M_{\mathrm{DO}}$ than the uninfected specimens. We found no significant effects caused by the rest of the parasites that 
were analysed, i.e. Lasiotocus mulli (Stossich, 1883), Proctotrema bacilliovatum (Odhner, 1911), Ascarophis mullusi (Naidenova \& Nikolaeva, 1968) and Cucullanus longicollis (Stossich, 1899).

\section{Discussion}

This study provides important new data on aspects of health and reproduction of red mullet, an exploited marine species, with particular focus on the links between parasitism, condition and reproductive capacity. We found that red mullet is a batch spawner with an income breeding strategy, an asynchronous development of oocytes and indeterminate fecundity. We also found that the parasites, Opecoeloides furcatus and Hysterothylacium spp., affect the condition and reproduction of this species.

The results of the histological observation of ovaries, coupled with the gonado-somatic index analysis show that the spawning period of $M$. barbatus collected in the western Mediterranean Sea takes place in spring-summer, with a peak of spawning activity in May and June, which coincides with data provided by Tsikliras et al. (2010). The fact that females in the regressing phase appeared throughout the spawning season may indicate that, although the spawning season for the species extends for several months, the individual spawning period might be much shorter.

The oocyte diameter-frequency distributions showed, for the first time, an asynchronous development of oocytes and that $M$. barbatus is a batch spawner. The stage-specific oocyte diameter showed a gradual increase and a slight overlapping between the diameters of cortical alveolar and vitellogenic oocytes. The absence of a hiatus separating the diameter of yolked oocytes from the one of unyolked oocytes indicates an indeterminate fecundity, i.e. the annual fecundity is not fixed before the onset of spawning and unyolked oocytes continue to mature and to be spawned during the spawning season (Murua et al., 2003). Despite the lack of published data on the oocyte recruitment pattern of this species, Anastasopoulou and Saborido-Rey (2011) showed that the recruitment of oocytes from primary growth to secondary growth stages continues throughout an individual's spawning period, indicating an indeterminate strategy which is consistent with our observations. In addition, the high levels of atresia observed in the regressing phase of our specimens also indicated an indeterminate fecundity, since females have to resorb the over production of secondary growth oocytes (Murua \& Saborido-Rey, 2003; Murua \& Motos, 2006).

The results of this study indicate that the total length and the eviscerated mass of $M$. barbatus originating from the western Mediterranean Sea are good predictors of its batch fecundity, as also reported in Turkish waters, such as the Aegean and Levantine Sea (Tirasin et al., 2007) or the eastern Black Sea (Aydın \& Karadurmuş, 2013). It was observed that the number of eggs increases as a power of the length of the fish and linearly with its mass. It can therefore be assumed that large specimens have a higher reproductive capacity than smaller ones. This result provides further support for the hypothesis that, for many fishes, the removal of large individuals can adversely affect the reproductive potential of species (Birkeland \& Dayton, 2005; Lloret et al., 2012b). Concerning egg quality, as measured by the hydrated oocyte dry mass, no previous studies were found with which to compare the results, thus we consider that future studies should take this variable into account.

The results of this study concur with the comprehensive study by Carreras-Aubets et al. (2012) and indicate that although $M$. barbatus can harbour a wide range of helminths, the most 
prevalent and abundant parasites are the digenean Opecoeloides furcatus and the nematode Hysterothylacium fabri. Our analysis of the parasitism throughout the different ovarian developmental phases of the host showed that there were no changes in the intensities of infection of any of the parasites through the reproductive cycle (although differences were found in the prevalence of $O$. furcatus, which was higher in specimens in the spawning capable phase than those in the regenerating phase). The fact that there is no reduction in the number of parasites in fish in the spawning capable phase compared to other phases would indicate that red mullet continues to feed during reproduction since, in most cases, fish become infected when actively feeding. If this is so, it would imply an income breeding strategy. In relation to this, while it is true that some authors found that M. barbatus curtails feeding during the spawning season in spring-summer (Vassilopoulou \& Papaconstantinou, 1993; Chérif et al., 2011), others have argued that the levels of vacuity (empty stomachs) are very low throughout the year (Esposito et al., 2014) or that M. barbatus actually feed intensely during the reproductive period (Bizsel, 1987).

The results of this study show that there is no decrease in the lipids stored in the muscle as the gonads develop, indicating that reproduction is fuelled by direct food intake. Moreover, the positive correlation found between lipid content in muscle and in the gonads reinforces the hypothesis that $M$. barbatus does not mobilize lipids from the muscle to the gonads. Similarly, Lloret et al. (2007) analysed the total lipid content in muscle and gonads of pre-spawning females of $M$. barbatus and also found that, although $M$. barbatus allocates lipid reserves to the gonad during the reproductive period, there was no depletion of the muscle lipids. These results provide further evidence that $M$. barbatus is an income breeder rather than a capital breeder.

The evidence that $M$. barbatus continue feeding throughout the spawning season coupled with their income breeding strategy is consistent with their indeterminate fecundity. That is to say, the number of eggs is not fixed before the onset of the spawning season but, instead, is adjusted to food intake, without reliance on stored energy (Rijnsdorp \& Witthames, 2005). However, it should be noted that some authors have pointed out that the boundaries between capital/income breeding and determinate/indeterminate fecundity are not as clear as had previously been assumed (Saborido-Rey et al., 2010; Ganias, 2013). For example, Domínguez-Petit et al. (2010) argued that for the European hake, Merluccius merluccius, in the northeastern Atlantic, gonadal development was at the expense of food intake, whereas Ferrer-Maza et al. (2014) has shown that, in the northwestern Mediterranean, this species is a capital breeder most of the year except in summer, when the abundance of its prey is at its peak in the Mediterranean. Thus, spawning strategies may be flexible within species and may depend on the availability of food. There is a well-documented distinction between capital breeders and income breeders, but there are also species that use a variety of mixed-breeding strategies (Houston et al., 2006; McBride et al., 2013). It seems probable that some species of fish may be capable of adopting either a capital or income strategy, or a blend of both in response to internal or external conditions.

The study of the relationships between parasitism, condition and reproduction of fish has highlighted that the specimens of $M$. barbatus in the spawning capable phase infected by the digenean Opecoeloides furcatus showed a lower lipid musculo-somatic index than uninfected specimens. O. furcatus, like most digeneans, is a parasite of the digestive tract where it feeds on mucus, epithelial cells and probably some of the host's gut content. This result might indicate a negative effect of $O$. furcatus on the energy reserves of $M$. barbatus, especially in the spawning season when fish are dividing their energy consumption between maintaining fitness and reproduction. With regard to the latter, parasitism seems to affect reproduction by causing quantitative and qualitative changes in the spawning. Although specimens infected by the 
nematodes Hysterothylacium aduncum and $H$. fabri showed higher fecundity than uninfected ones, it was found - at least in the case of those infected by $\mathrm{H}$. fabri - that there was a lower mass of hydrated oocytes. Accordingly, it can be hypothesized that nematodes belonging to the genus Hysterothylacium cause a reduction in the quality of the eggs, but in response, female $M$. barbatus try to compensate for this by producing a higher number of eggs.

As mentioned in the introduction, a limited number of studies have dealt with the effects of parasitism on the energy reserves or the reproduction of marine species. Fogelman et al. (2009) found that female five-lined cardinalfish, Cheilodipterus quinquelineatus Cuvier 1828, infected by the isopod Anilocra apogonae Bruce 1987, had fewer and smaller eggs than uninfected fish. Sasal et al. (2001) also found that the females of the gobiid fish Gobius bucchichii Steindachner 1870, infected by the acanthocephalan Acanthocephaloides propinquus Dujardin 1845, showed a reduction in egg production. With regard to exploited fish, there are contradictory results about the effects of nematodes on energy reserves. For example, while Shchepkina (1980) found that the anchovy, Engraulis encrasicolus, infected by Contracaecum sp. showed lower lipid content, Sajiki et al. (1992) found that E. japonicus infected by Anisakis sp. did not experience a depletion in the total lipid content, but there was an increase in the free fatty acids in their viscera. Finally, Ferrer-Maza et al. (2014) have recently revealed that the anisakid nematodes, especially Anisakis pegreffi Campana-Rouget \& Biocca 1955, negatively affect the condition of the European hake, Merluccius merluccius, mainly when these fish are allocating their energy reserves to gonadal development, while infections by other parasites do not affect them significantly.

Along with those of previous studies, our results have demonstrated that parasitism, condition and reproduction are closely linked. The physical health of exploited stocks, which depends on the health and reproductive capacity of the individuals, is an essential element of sustainable and profitable fisheries (Lloret et al., 2012a). Therefore, the results of this study, especially those concerning the effects of parasites on condition and reproduction, may have an important impact on the development of management strategies and research involving other species, whether wild or captive-bred.

In summary, the present study not only provides basic knowledge on the reproduction, condition and parasitism of Mullus barbatus in the western Mediterranean Sea, but also some important implications of their relationships. The results lead us to suggest that $M$. barbatus should be classified as an iteroparous batch spawner species with an income breeding strategy, an asynchronous development of oocytes and indeterminate fecundity. This study also showed that larger females have a higher fecundity, confirming that older spawners contribute heavily to reproduction. We have also concluded that although $M$. barbatus can harbour a wide range of helminths, only the most abundant and prevalent ones (i.e. the digenean Opecoeloides furcatus and the nematodes Hysterothylacium spp.) significantly affect the condition and reproduction of $M$. barbatus during the spawning season. Furthermore, the effects are complex: the digenean $O$. furcatus causes a reduction in the energy reserves of fish, whereas infection by the nematodes Hysterothylacium spp. results in a rise in egg production but impaired egg quality. This shows that the relationships between parasitism, condition and reproduction are not always evident in income breeder fish. We consider, therefore, that further research regarding the role of the energy reserves and the nutrient acquisition would be of great help in understanding the energy cost of reproduction and parasitism. 


\section{Acknowledgements}

We are grateful to our colleagues at the University of Girona (Animal Biology-Ichthyology Research Group) for their collaboration in the laboratory work and, especially, to A. El Aoussimi for his helpful assistance during on-board fish sampling. Thanks are also given to the crew of the R/V Cornide de Saavedra (IEO, Spain) for technical and scientific support during the MEDITS GSA-06 trawl surveys. We also wish to extend our gratitude to R. A. Bray (NHM, London) for his kind help with the digenean identification and the Guest Editor and the anonymous referees for their helpful comments and suggestions on earlier drafts of the manuscript. This study was carried out within the framework of a research project (ref. CTM2009-08602) funded by the Spanish Ministry of Science and Innovation, whereby D. Ferrer-Maza benefited from a FPI predoctoral fellowship (ref. BES-2010-032618). J. Lloret benefited from a "Ramón y Cajal" research contract from the Spanish Ministry of Economy and Competitiveness.

\section{References}

Adams, S. M., 1999. Ecological role of lipids in the health and success of fish populations In Arts, M. T., \& B. C. Wainnmann (eds), Lipids in freshwater ecosystems. Springer, New York: $132-153$.

Alonso-Fernández, A., A. C. Vallejo, F. Saborido-Rey, H. Murua, \& E. A. Trippel, 2009. Fecundity estimation of Atlantic cod (Gadus morhua) and haddock (Melanogrammus aeglefinus) of Georges Bank: Application of the autodiametric method. Fisheries Research 99: 47-54.

Anastasopoulou, A., \& F. Saborido-Rey, 2011. Reproductive ecology of Mullus barbatus in eastern Mediterranean Sea. In Book of abstracts of the Fish Reproduction and Fisheries (FRESH) Final Conference, held on 16-20 May 2011 in Vigo, Spain. http://freshcost.quadralia.net/fresh-final-conference/.

Aydın, M., \& U. Karadurmuş, 2013. An investigation on age, growth and biological characteristics of red mullet (Mullus barbatus ponticus, Essipov, 1927) in the Eastern Black Sea. Iranian Journal of Fisheries Sciences 12: 277-288.

Bagamian, K. H., D. C. Heins, \& J. A. Baker, 2004. Body condition and reproductive capacity of three-spined stickleback infected with the cestode Schistocephalus solidus. Journal of Fish Biology 64: 1568-1576.

Barret, J. A., 1986. Host-parasite interactions and systematics. In Stone, A. R., \& D. L. Hawksworth (eds), Coevolution and Systematics. Oxford University Press Inc., Oxford: $1-17$.

Bean, M. G., \& T. H. Bonner, 2009. Impact of Bothriocephalus acheilognathi (Cestoda: Pseudophyllidea) on Cyprinella lutrensis Condition and Reproduction. Journal of Freshwater Ecology 24: 383-391.

Benjamini, Y., \& Y. Hochberg, 1995. Controlling the false discovery rate: A practical and powerful approach to multiple testing. Journal of the Royal Statistical Society 57: 289300 . 
Birkeland, C., \& P. K. Dayton, 2005. The importance in fishery management of leaving the big ones. Trends in Ecology and Evolution 20: 356-358.

Bizsel, K. C., 1987. Seasonal variations in the diel diet of the red mullets (Mullus barbatus L.) in the northern Sicilian Basin. Middle East Technical University, 87 pp.

Bray, R. A., D. I. Gibson, \& A. Jones, 2008. Keys to the trematoda (Volume 3). CAB International, Wallingford, $848 \mathrm{pp}$.

Brown-Peterson, N. J., D. M. Wyanski, F. Saborido-Rey, B. J. Macewicz, \& S. K. LowerreBarbieri, 2011. A Standardized Terminology for Describing Reproductive Development in Fishes. Marine and Coastal Fisheries 3: 52-70.

Bush, A. O., K. D. Lafferty, J. M. Lotz, \& A. W. Shostak, 1997. Parasitology meets ecology on its own terms: Margolis et al. Revisited. Journal of Parasitology 83: 575-583.

Carreras-Aubets, M., F. E. Montero, A. Kostadinova, \& M. Carrassón, 2012. Parasite communities in the red mullet, Mullus barbatus L., respond to small-scale variation in the levels of polychlorinated biphenyls in the Western Mediterranean. Marine Pollution Bulletin 64: 1853-1860.

Carreras-Aubets, M., F. E. Montero, F. Padrós, S. Crespo, \& M. Carrassón, 2011. Parasites and hystopathology of Mullus barbatus and Citharus linguatula (Pisces) from two sites in the NW Mediterranean with different degrees of pollution. Scientia Marina 75: 369-378.

Chérif, M., M. M. Ben Amor, S. Selmi, H. Gharbi, H. Missaoui, \& C. Capapé, 2011. Food and feeding habits of the red mullet, Mullus barbatus (Actinopterygii: Perciformes:

Mullidae), off the northern Tunisian coast (central Mediterranean). Acta Ichthyologica Et Piscatoria 41: 109-116.

Desbrosses, P., 1935. Contribution a la connaissance de la biologie du rouget-barbet en Atlantique nord. Revue des Travaux de l'Institut des Pêches Maritimes IV (3): 249-270.

Domínguez-Petit, R., F. Saborido-Rey, \& I. Medina, 2010. Changes of proximate composition, energy storage and condition of European hake (Merluccius merluccius, L. 1758) through the spawning season. Fisheries Research 104: 73-82.

Durieux, E. D. H., R. Galois, M.-L. Bégout, P. Sasal, \& F. Lagardère, 2007. Temporal changes in lipid condition and parasitic infection by digenean metacercariae of young-of-year common sole Solea solea (L.) in an Atlantic nursery ground (Bay of Biscay, France). Journal of Sea Research 57: 162-170.

Esposito, V., F. Andaloro, D. Bianca, A. Natalotto, T. Romeo, G. Scotti, \& L. Castriota, 2014. Diet and prey selectivity of the red mullet, Mullus barbatus (Pisces: Mullidae), from the southern Tyrrhenian Sea: the role of the surf zone as a feeding ground. Marine Biology Research Taylor \& Francis 10: 167-178.

FAO/General Fisheries Commission for the Mediterranean, 2012. Report of the Fourteenth Session of the Scientific Advisory Committee. Sofia, Bulgaria, 20-24 February 2012. 
FAO Fisheries and Aquaculture Report $\mathrm{n}^{\circ} .1001$. FAO, Rome, $200 \mathrm{pp}$.

http://www.fao.org/docrep/015/i2702b/i2702b.pdf.

Ferrer-Maza, D., J. Lloret, M. Muñoz, E. Faliex, S. Vila, \& P. Sasal, 2014. Parasitism, condition and reproduction of the European hake (Merluccius merluccius) in the northwestern Mediterranean Sea. ICES Journal of Marine Science 71: 1088-1099.

Fischer, W., M. Schneider, \& M. L. Bauchot, 1987. Fiches FAO d'identification des espèces pour les besoins de la peche. Mediterranée et Mer Noire. Zone de peche 37. Volume II: Vertébrés. Fiches FAO d'identification des espèces pour les besoins de la peche. FAO, Rome, 769 pp.

Fogelman, R. M., A. M. Kuris, \& A. S. Grutter, 2009. Parasitic castration of a vertebrate: Effect of the cymothoid isopod, Anilocra apogonae, on the five-lined cardinalfish, Cheilodipterus quinquelineatus. International Journal for Parasitology 39: 577-583.

Francová, K., \& M. Ondračková, 2013. Overwinter body condition, mortality and parasite infection in two size classes of 0+ year juvenile European bitterling Rhodeus amarus. Journal of Fish Biology 82: 555-568.

Ganias, K., 2013. Determining the indeterminate: Evolving concepts and methods on the assessment of the fecundity pattern of fishes. Fisheries Research 138: 23-30.

Gibson, D. I., A. Jones, \& R. A. Bray, 2002. Keys to the trematoda (Volume 1). CAB International, Wallingford, $544 \mathrm{pp}$.

Guidelli, G., W. L. G. Tavechio, R. M. Takemoto, \& G. C. Pavanelli, 2011. Relative condition factor and parasitism in anostomid fishes from the floodplain of the Upper Paraná River, Brazil. Veterinary Parasitology 177: 145-151.

Houston, A. I., P. A. Stephens, I. L. Boyd, K. C. Harding, \& J. M. McNamara, 2006. Capital or income breeding? A theoretical model of female reproductive strategies. Behavioral Ecology 18: 241-250.

Jones, A., R. A. Bray, \& D. I. Gibson, 2005. Keys to the trematoda (Volume 2). CAB International, Wallingford, $768 \mathrm{pp}$.

Khan, R. A., \& D. Lacey, 1986. Effect of concurrent infections of Lernaeocera Branchialis (Copepoda) and Trypanosoma murmanensis (Protozoa) on Atlantic cod, Gadus morhua. Journal of Wildlife Diseases 22: 201-208.

Kokokiris, L., A. Stamoulis, N. Monokrousos, \& S. Doulgeraki, 2014. Oocytes development, maturity classification, maturity size and spawning season of the red mullet (Mullus barbatus barbatus Linnaeus, 1758). Journal of Applied Ichthyology 30: 20-27.

Lloret, J., M. Demestre, \& J. Sánchez-Pardo, 2007. Lipid reserves of red mullet (Mullus barbatus) during pre-spawning in the northwestern Mediterranean. Scientia Marina 71: 269-277. 
Lloret, J., E. Faliex, G. E. Shulman, J. A. Raga, P. Sasal, M. Muñoz, M. Casadevall, A. E. AhuirBaraja, F. E. Montero, A. Repullés-Albelda, M. Cardinale, H. J. Rätz, S. Vila, \& D. Ferrer-Maza, 2012a. Fish Health and Fisheries, Implications for Stock Assessment and Management: The Mediterranean Example. Reviews in Fisheries Science 20: 165-180.

Lloret, J., R. Galzin, L. Gil de Sola, A. Souplet, \& M. Demestre, 2005. Habitat related differences in lipid reserves of some exploited fish species in the north-western Mediterranean continental shelf. Journal of Fish Biology 67: 51-65.

Lloret, J., M. Muñoz, \& M. Casadevall, 2012b. Threats posed by artisanal fisheries to the reproduction of coastal fish species in a Mediterranean marine protected area. Estuarine, Coastal and Shelf Science 113: 133-140.

Lloret, J., G. Shulman, \& R. M. Love, 2014. Condition and Health Indicators of Exploited Marine Fishes. Whiley Blackwell, Oxford, 262 pp.

Lowerre-Barbieri, S. K., \& L. R. Barbieri, 1993. A new method of oocyte separation and preservation for fish reproduction studies. Fishery Bulletin 91: 165-170.

Lowerre-Barbieri, S. K., N. J. Brown-Peterson, H. Murua, J. Tomkiewicz, D. M. Wyanski, \& F. Saborido-Rey, 2011. Emerging Issues and Methodological Advances in Fisheries Reproductive Biology. Marine and Coastal Fisheries 3: 32-51.

Martínez-Vicaria, A., J. Martín-Sánchez, P. Illescas, A. M. Lara, M. Jiménez-Albarrán, \& A. Valero, 2000. The occurrence of two opecoeliid digeneans in Mullus barbatus and $M$. surmuletus from the Spanish south-eastern Mediterranean. Journal of Helminthology 74: 161-164.

McBride, R. S., S. Somarakis, G. R. Fitzhugh, A. Albert, N. A. Yaragina, M. J. Wuenschel, A. Alonso-Fernández, \& G. Basilone, 2013. Energy acquisition and allocation to egg production in relation to fish reproductive strategies. Fish and Fisheries (in press) http://doi.wiley.com/10.1111/faf.12043.

Muñoz, M., C. Dimitriadis, M. Casadevall, S. Vila, E. Delgado, J. Lloret, \& F. Saborido-Rey, 2010. Female reproductive biology of the bluemouth Helicolenus dactylopterus dactylopterus: spawning and fecundity. Journal of Fish Biology 77: 2423-2442.

Murua, H., G. Kraus, F. Saborido-Rey, P. R. Witthames, A. Thorsen, \& S. Junquera, 2003. Procedures to Estimate Fecundity of Marine Fish Species in Relation to their Reproductive Strategy. Journal of Northwest Atlantic Fishery Science 33: 33-54.

Murua, H., \& L. Motos, 2006. Reproductive strategy and spawning activity of the European hake Merluccius merluccius (L.) in the Bay of Biscay. Journal of Fish Biology 69: 1288-1303.

Murua, H., \& F. Saborido-Rey, 2003. Female Reproductive Strategies of Marine Fish Species of the North Atlantic. Journal of Northwest Atlantic Fishery Science 33: 23-31.

Naidenova, N. N., \& V. M. Nikolaeva, 1968. Nematode fauna of some benthic fish of the Mediterranean Basin. Biologiya Morya 14: 63-82. 
Ondracková, M., K. Francová, M. Dávidová, M. Polacik, \& P. Jurajda, 2010. Condition status and parasite infection of Neogobius kessleri and N. melanostomus (Gobiidae) in their native and non-native area of distribution of the Danube River. Ecological Research 25: $857-866$.

Petter, A. J., C. Lèbre, \& B. M. Radujkovic, 1984. Nematode parasites of osteichthyen fish of the southern Adriatic. Acta Adriatica 25: 205-221.

Petter, A. J., \& C. Maillard, 1987. Ascarids of fishes from Western Mediterranean sea. Bulletin du Muséum National d'Histoire Naturelle. Section A, Zoologie, Biologie et Écologie Animales 9: 773-798.

Petter, A. J., \& C. Maillard, 1988. Larval Ascarids parasites of fishes from western Mediterranean sea. Bulletin du Muséum National d'Histoire Naturelle. Section A, Zoologie, Biologie et Écologie Animales Muséum national d'histoire naturelle 10: 347369.

Ramdane, Z., J. P. Trilles, K. Mahé, \& R. Amara, 2013. Metazoan ectoparasites of two teleost fish, Boops boops (L.) and Mullus barbatus barbatus L. from Algerian coast: Diversity, parasitological index and impact of parasitism. Cybium 37: 59-66.

Reiczigel, J. \& L. Rózsa, 2005. Quantitative Parasitology 3.0. Budapest. Distributed by the authors. Available at http://www.zoologia.hu/qp/qp.html

Rijnsdorp, A. D., \& P. R. Witthames, 2005. Ecology of reproduction In Gibson, R. N. (ed), Flatfishes: Biology and Exploitation. Fish and Aquatic Resources Series 9. Blackwell Science, Oxford: 68-93.

Roncarati, A., G. Brambilla, A. Meluzzi, A. L. Iamiceli, R. Fanelli, I. Moret, A. Ubaldi, R. Miniero, F. Sirri, P. Melotti, \& A. di Domenico, 2012. Fatty acid profile and proximate composition of fillets from Engraulis encrasicholus, Mullus barbatus, Merluccius merluccius and Sarda sarda caught in Tyrrhenian, Adriatic and Ionian seas. Journal of Applied Ichthyology 28: 545-552.

Rózsa, L., J. Reiczigel, \& G. Majoros, 2000. Quantifying parasites in samples of hosts. Journal of Parasitology 86: 228-232.

Saborido-Rey, F., O. S. Kjesbu, \& A. Thorsen, 2003. Buoyancy of Atlantic cod larvae in relation to developmental stage and maternal influences. Journal of Plankton Research 25: 291307.

Saborido-Rey, F., H. Murua, J. Tomkiewicz, \& S. Lowerre-Barbieri, 2010. Female Reproductive Strategies: An Energetic Balance Between Maturation, Growth and Egg Production. In Wyanski, D. M., \& N. J. Brown-Peterson (eds), Proceedings of the 4th Workshop on Gonadal Histology of Fishes, held on 16-19 June 2009 in El Puerto de Santa María, Spain: 15-18. http://hdl.handle.net/10261/24937.

Sajiki, J., K. Takahashi, Y. Hayashi, Y. Ando, M. Kaneda, \& T. Hamazaki, 1992. Fatty acid composition in anchovy (Engraulis japonicus) infected with Anisakis simplex. Japanese Journal of Toxicology and Environmental Health 38: 361-365. 
Sasal, P., E. Faliex, I. De Buron, \& S. Morand, 2001. Sex discriminatory effect of the acanthocephalan Acanthocephaloides propinquus on a gobid fish Gobius bucchichii. Parasite 8: 231-236.

Shahidi, F., 2001. Extraction and Measurement of Total Lipids In Wrolstad, R. E. (ed), Current Protocols in Food Analytical Chemistry. John Wiley \& Sons, New York: 1-11.

Shchepkina, A. M., 1980. Lipid composition of the tissues of Engraulis encrasicholus during its annual cycle and in infection with larvae of the nematode Contracaecum aduncum. Ekologiya Morya 3: 33-39.

Tirasin, E. M., A. Unluoglu, \& B. Cihangir, 2007. Fecundity of red mullet (Mullus barbatus L., 1758) along the Turkish coasts of the Mediterranean sea. Rapport Commission International pour l'Exploration Scientifique de la Mer Méditerranée 38: 614.

Tserpes, G., F. Fiorentino, D. Levi, A. Cau, M. Murenu, A. Zamboni, \& C. Papaconstantinou, 2002. Distribution of Mullus barbatus and M. surmuletus (Osteichthyes: Perciformes) in the Mediterranean continental shelf: implications for management. Scientia Marina 66: $39-54$

Tsikliras, A. C., E. Antonopoulou, \& K. I. Stergiou, 2010. Spawning period of Mediterranean marine fishes. Reviews in Fish Biology and Fisheries 20: 499-538.

Vassilopoulou, V., \& C. Papaconstantinou, 1993. Feeding habits of red mullet (Mullus barbatus) in a gulf in western Greece. Fisheries Research 16: 69-83.

Verhoeven, K. J. F., K. L. Simonsen, \& L. M. McIntyre, 2005. Implementing false discovery rate control: increasing your power. Oikos 108: 643-647. 
Table 1 Results of the analysis of variance for the response variables [natural-log-transformed lipid musculo-somatic index ( $\left.I_{\mathrm{LM}}\right)$, lipid gonadosomatic index $\left(I_{\mathrm{LG}}\right)$ and relative batch fecundity $\left.\left(F_{\mathrm{Brel}}\right)\right]$, and the effects of the explanatory variables [year, total length $\left(L_{\mathrm{T}}\right)$, latitude and depth of capture]. The deviance explained by each variable is also shown. No significant interactions between explanatory variables were found.

\begin{tabular}{|c|c|c|c|c|c|c|}
\hline $\begin{array}{l}\text { Response } \\
\text { variable }\end{array}$ & $\begin{array}{l}\text { Explanatory } \\
\text { variables }\end{array}$ & Df & MS & $F$ & $P$ & $\begin{array}{l}\mathrm{DE} \\
(\%)\end{array}$ \\
\hline \multirow[t]{6}{*}{$I_{\mathrm{LM}}$} & LATITUDE & & & & & - \\
\hline & DEPTH & & & & & - \\
\hline & YEAR & 2 & 1.985 & 6.552 & 0.002 & 7.9 \\
\hline & $L_{\mathrm{T}}$ & 1 & 1.969 & 6.502 & 0.012 & 4.1 \\
\hline & Corrected model & 3 & 2.134 & 7.047 & 0.000 & 12.2 \\
\hline & Error & 152 & 0.303 & & & \\
\hline \multirow[t]{6}{*}{$I_{\mathrm{LG}}$} & LATITUDE & & & & & - \\
\hline & DEPTH & & & & & - \\
\hline & YEAR & 2 & 0.255 & 10.406 & 0.000 & 20.0 \\
\hline & $L_{\mathrm{T}}$ & 1 & 0.219 & 8.904 & 0.004 & 9.7 \\
\hline & Corrected model & 3 & 0.277 & 11.282 & 0.000 & 29.0 \\
\hline & Error & 83 & 0.025 & & & \\
\hline \multirow[t]{6}{*}{$F_{\text {Brel }}$} & LATITUDE & & & & & - \\
\hline & YEAR & & & & & - \\
\hline & $L_{\mathrm{T}}$ & 1 & 29005.964 & 7.946 & 0.006 & 8.5 \\
\hline & DEPTH & 1 & 27065.881 & 7.415 & 0.008 & 7.9 \\
\hline & Corrected model & 2 & 20022.160 & 5.485 & 0.006 & 11.3 \\
\hline & Error & 86 & 3650.366 & & & \\
\hline
\end{tabular}

Df: degrees of freedom; MS: mean square; DE: deviance explained 
Table 2 Taxonomic composition, number of infected hosts, prevalence $\left(P_{\mathrm{P}}\right)$ and intensity of metazoan parasites found in Mullus barbatus from the western Mediterranean Sea. The parasite developmental stage, the site of infection and the ovarian developmental phase of hosts are also shown.

\begin{tabular}{|c|c|c|c|c|c|c|c|c|}
\hline \multirow{2}{*}{ Parasite species } & \multirow{2}{*}{ Stage } & \multirow{2}{*}{ Site } & \multirow{2}{*}{$\begin{array}{l}\text { Ovarian developmental } \\
\text { phase }\end{array}$} & \multirow{2}{*}{$\begin{array}{l}\text { Infected } \\
\text { hosts }\end{array}$} & \multirow{2}{*}{$\begin{array}{c}P_{\mathrm{P}} \\
(n=335)\end{array}$} & \multicolumn{3}{|c|}{ Intensity } \\
\hline & & & & & & Min-Max & Mean \pm s.d. & $\begin{array}{l}\text { Median } \\
95 \% C I\end{array}$ \\
\hline \multicolumn{9}{|l|}{ Digenea } \\
\hline Derogenes latus (Janiszewska, 1953) & $A$ & $D$ & $D E V, S C$ & 6 & 1.79 & $(1-7)$ & $2.50 \pm 2.51$ & $1.00-4.50$ \\
\hline Lasiotocus mulli (Stossich, 1883)* & $A$ & $D$ & $R E G, R E G R$ & 2 & 0.60 & $(1-4)$ & $2.50 \pm 2.12$ & $1.00-2.50$ \\
\hline Lecithocladium excisum (Rudolphi, 1819) Lühe, 1901 & $A$ & $D$ & $D E V, S C$ & 2 & 0.60 & $(2-3)$ & $2.50 \pm 0.71$ & $2.00-3.00$ \\
\hline Opecoeloides furcatus (Bremser in Rudolphi, 1819)* & $A$ & $D$ & $R E G, D E V, S C, R E G R$ & 186 & 55.52 & $(1-53)$ & $6.97 \pm 8.66$ & $5.88-8.41$ \\
\hline Proctotrema bacilliovatum (Odhner, 1911)* & $A$ & $D$ & $D E V, S C, R E G R$ & 4 & 1.19 & $(1-7)$ & $3.25 \pm 2.63$ & $1.50-5.75$ \\
\hline Unidentified immature specimens & $L$ & $D$ & $S C, R E G R$ & 6 & 1.79 & $(1-15)$ & $3.50 \pm 5.65$ & $1.00-10.33$ \\
\hline \multicolumn{9}{|l|}{ Nematoda } \\
\hline Ascarophis mullusi (Naidenova \& Nikolaeva, 1968)* & $A$ & $D$ & $D E V, S C, R E G R$ & 4 & 1.19 & $(1-5)$ & $2.25 \pm 1.89$ & $1.00-4.00$ \\
\hline Contracaecum sp. & $L 3$ & $D, M$ & $S C, R E G R$ & 2 & 0.60 & $(1-1)$ & 1 & - \\
\hline Cucullanus longicollis (Stossich, 1899) & A & $D$ & $S C, R E G R$ & 13 & 3.88 & $(1-6)$ & $1.85 \pm 1.41$ & $1.31-2.85$ \\
\hline Hysterothylacium aduncum (Rudolphi, 1802) & $L 3, L 4, A$ & $D, M$ & $R E G, D E V, S C, R E G R$ & 29 & 8.66 & $(1-4)$ & $1.55 \pm 0.78$ & $1.28-1.83$ \\
\hline Hysterothylacium fabri (Rudolphi, 1819) & $L 3, L 4$ & $D, L, M$ & $R E G, D E V, S C, R E G R$ & 214 & 63.88 & $(1-42)$ & $3.95 \pm 5.94$ & $3.28-4.81$ \\
\hline \multicolumn{9}{|l|}{ Cestoda } \\
\hline Tetraphyllidean plerocercoids & $P$ & $D$ & $R E G, D E V, S C$ & 6 & 1.79 & $(1-3)$ & $1.50 \pm 0.84$ & $1.00-2.17$ \\
\hline \multicolumn{9}{|l|}{ Isopoda } \\
\hline Gnathia sp. (praniza larvae) & $L$ & $G$ & $S C, R E G R$ & 9 & 2.69 & $(1-7)$ & $2.67 \pm 1.94$ & $1.67-4.11$ \\
\hline
\end{tabular}

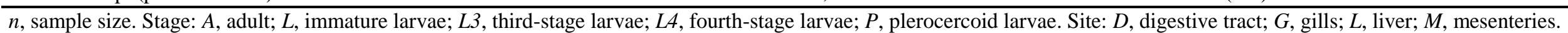
Ovarian developmental phase of hosts: $R E G$, regenerating; $D E V$, developing; $S C$, spawning capable; $R E G R$, regressing.

*Indicates a specialist parasite of mullets (Mullus spp.). 
Table 3 Results of Mann-Whitney U test used to verify the existence of differences between infected and uninfected Mullus barbatus and Spearman's Rank Correlation coefficient $(r s)$ used to evaluate possible relationships among the condition and reproduction variables and the individual intensity of parasitism. Only significant results $(P<0.05)$ are presented.

\begin{tabular}{|c|c|c|c|c|c|c|c|c|c|c|c|}
\hline \multirow{2}{*}{$\begin{array}{l}\text { Ovarian developmental phase } \\
(n)\end{array}$} & \multirow{2}{*}{ Parasite } & \multirow{2}{*}{ Variable } & \multicolumn{6}{|c|}{ Mann-Whitney U Test } & \multicolumn{3}{|c|}{ Spearman's Rank Correlation } \\
\hline & & & $n$ Uninf. & $n$ Inf. & $M d$ Uninf. & $M d$ Inf. & $U$ & $p^{\mathrm{a}}$ & $n$ & $r s$ & $p$ \\
\hline \multirow[t]{4}{*}{ Spawning capable (267) } & Opecoeloides furcatus & $I_{\mathrm{LM}}$ & 39 & 84 & -0.116 & -0.169 & 1126 & 0.005 & 123 & -0.278 & 0.002 \\
\hline & Hysterothylacium aduncum & $B_{\text {Frel }}$ & 82 & 7 & 232 & 250 & 155 & 0.044 & 89 & 0.211 & 0.047 \\
\hline & Hysterothylacium fabri & $B_{\text {Frel }}$ & 28 & 61 & 228 & 238 & 569 & 0.012 & 89 & 0.300 & 0.004 \\
\hline & Hysterothylacium fabri & $M_{\mathrm{DO}}$ & 28 & 61 & 0.013 & 0.011 & 546 & 0.006 & - & - & - \\
\hline
\end{tabular}

$n$, subsample size; Uninf., uninfected fish; Inf., infected fish; $M d$, variable median. Variables: $I_{\mathrm{LM}}$, adjusted log-transformed lipid musculo-somatic index; $B_{\text {Frel }}$, adjusted relative batch fecundity; $M_{\text {DO }}$, dry mass of oocytes.

${ }^{\text {a }}$ Asymptotic significances (2-tailed) are displayed for Mann-Whitney U tests with sample size above 10 in all groups, otherwise, exact significances [2*(1-tailed Sig.)] are given. 


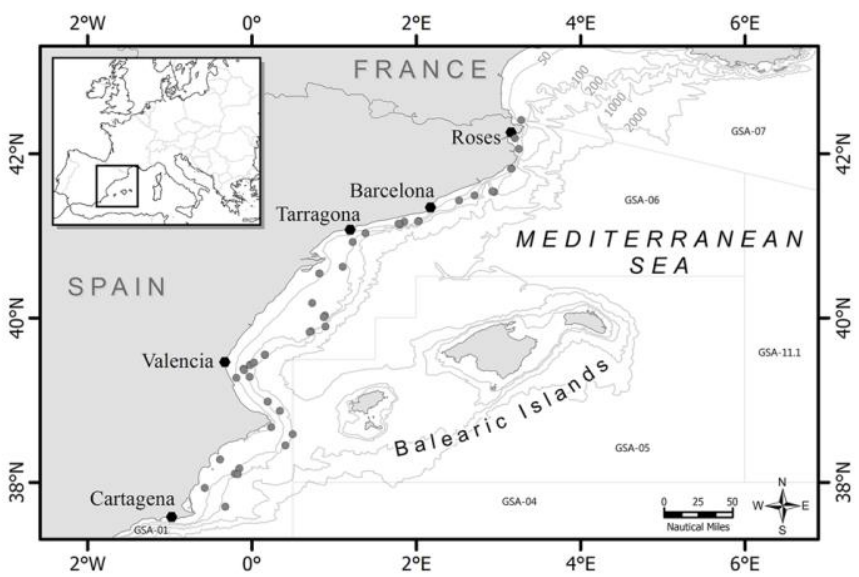

Fig. 1 Map of the western Mediterranean Sea showing the locations where Mullus barbatus were caught (FAO-GFCM geographical sub-area GSA-06, Northern Spain).

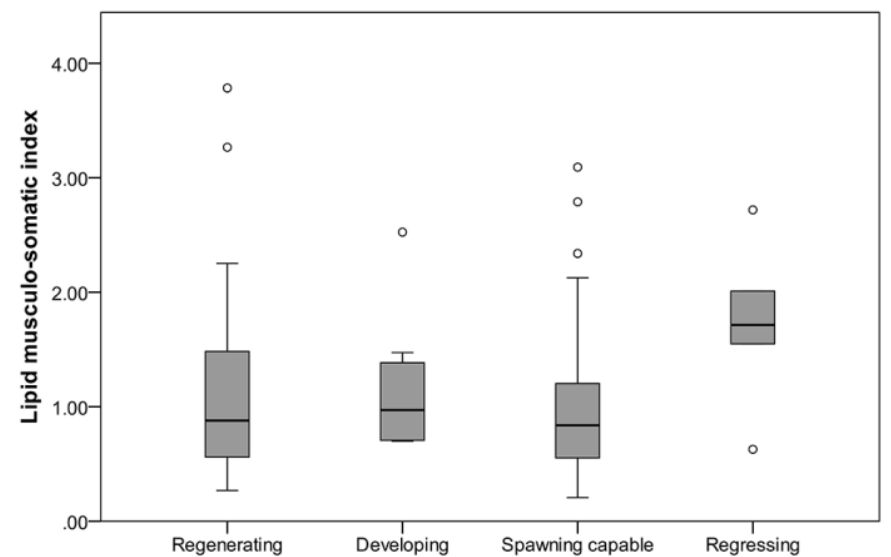

Fig. 2 Boxplots of lipid musculo-somatic index $\left(I_{\mathrm{LM}}\right)$ through the different ovarian developmental phases of female Mullus barbatus. Regenerating $(n=17)$, developing $(n$ $=11)$, spawning capable $(n=123)$, regressing $(n=5)$.

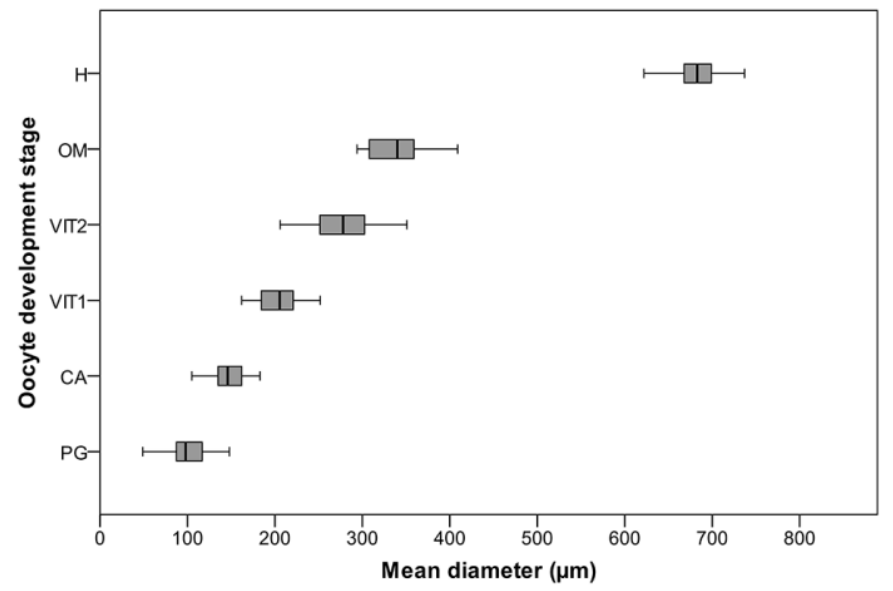

Fig. 3 Boxplots of the stage-specific oocyte diameter belonging to 10 randomly selected Mullus barbatus specimens in spawning capable phase. PG: Primary growth stage (at the perinucleolar stage), mean diameter $(\mu \mathrm{m}): 99 \pm 24(n=88)$; CA: Cortical alveolar stage, $148 \pm 18(n=94)$; VIT1: Primary stage of vitellogenesis, $204 \pm 23(n=76)$; 
VIT2: Secondary stage of vitellogenesis, $279 \pm 36(n=95)$; OM: Maturation stage, 340 $\pm 33(n=26) ; \mathrm{H}:$ Hydration stage, $684 \pm 23(n=247)$.

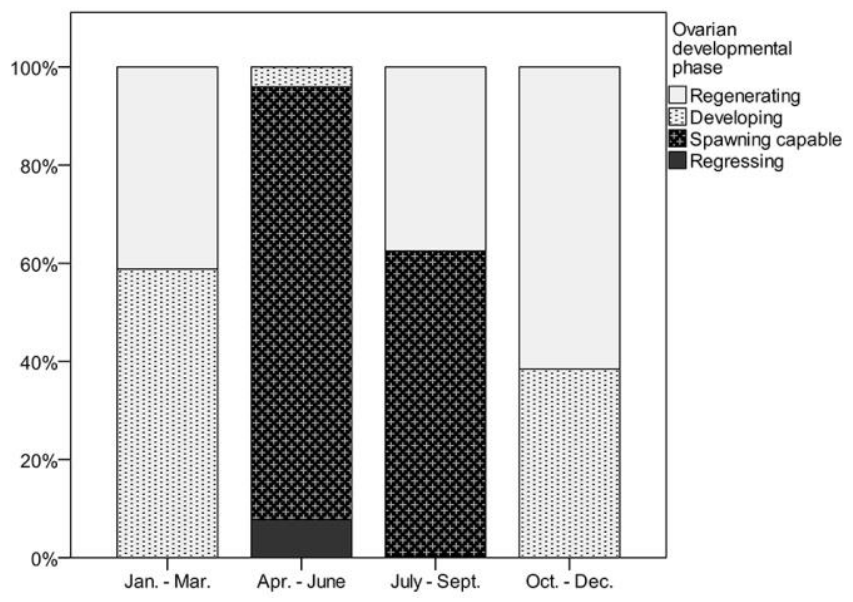

Fig. 4 Quarterly variations in the relative frequency of the ovarian developmental phases in Mullus barbatus (from January 2010 to May 2012).

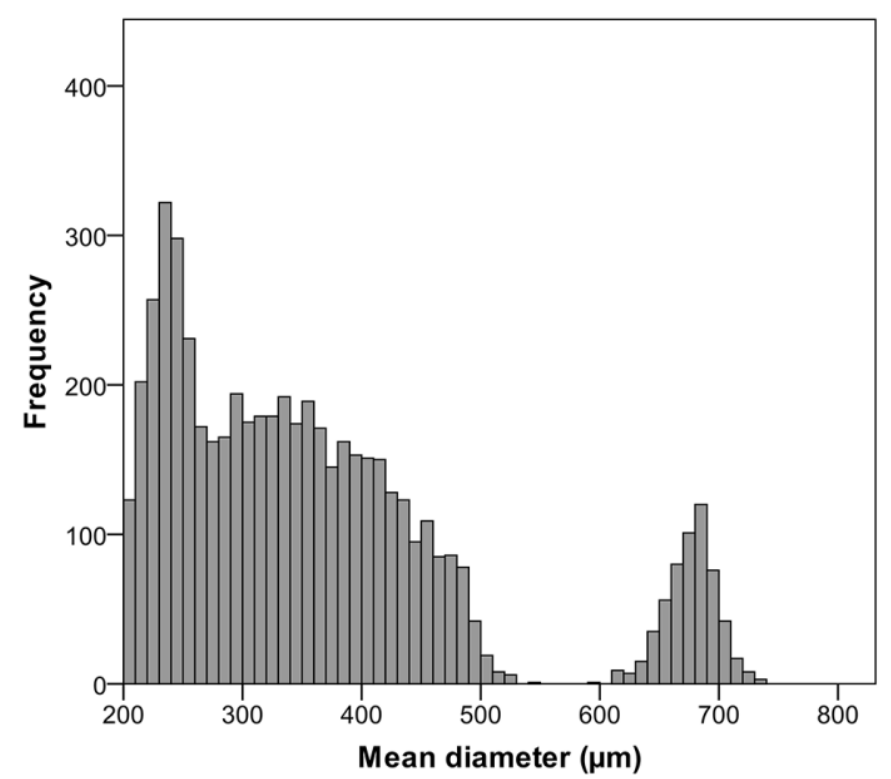

Fig. 5 Oocyte diameter-frequency distribution (over $200 \mu \mathrm{m}$ ) shown by most of the female Mullus barbatus with hydrated oocytes. This example corresponds to one female with $L_{\mathrm{T}}=21.4 \mathrm{~cm}$ and $F_{\mathrm{B}}=15664$ eggs. 

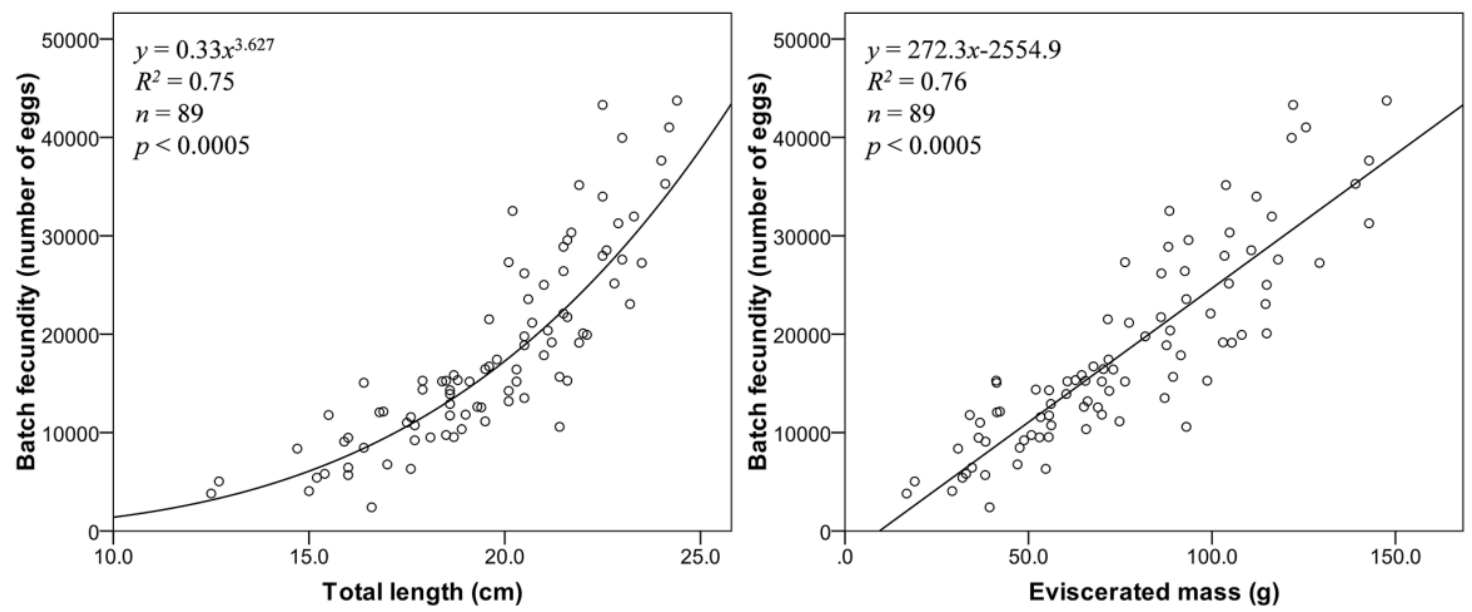

Fig. 6 Relation between batch fecundity and total length (power function regression), or eviscerated mass (linear regression) of female Mullus barbatus. 